\title{
ANÁLISE DO ENSINO E APRENDIZADO DO TEMA IMUNOLOGIA EM ESCOLAS DO MUNICÍPIO DE ITAPERUNA - RJ
}

\author{
Jonathas Corrêa BOTELHO ${ }^{1}$ \& Nathália Bastos Lima de ANDRADE ${ }^{2 *}$
}

1 Universidade Estadual do Norte Fluminense Darcy Ribeiro, Consórcio CEDERJ, Polo Bom Jesus do Itabapoana. Bom Jesus do Itabapoana, Rio de Janeiro, Brasil.

2 Instituto Federal Fluminense - Campus Quissamã. Quissamã, Rio de Janeiro, Brasil

*Autor para correspondência: nathalia.andrade@iff.edu.br

DOI: http://dx.doi.org/10.18571/acbm.182

\section{RESUMO}

Esta pesquisa analisou o processo de ensino-aprendizagem de Imunologia em escolas públicas e privadas do município de Itaperuna (RJ), verificar divergências na abordagem do tema e analisar as metodologias e materiais didáticos utilizados pelos professores. A pesquisa envolveu estudantes do $3^{\circ}$ ano do Ensino Médio e seus professores de Biologia. Foi aplicado um questionário com dez questões sobre Imunologia para os estudantes e realizada entrevistas com os professores de cada turma, para verificar como este tema é abordado em sala de aula e os materiais didáticos utilizados. Os estudantes obtiveram menos da metade dos acertos, demonstrando que ainda apresentam um raso conhecimento sobre Imunologia, decorrente da pouca atenção dada a este tema pelos professores das escolas avaliadas. Os resultados evidenciam a necessidade de discussões sobre o ensino deste tema e no fornecimento de alternativas para estimular práticas de ensino-aprendizagem de Imunologia, bem como popularizar este tópico tão comum no cotidiano.

Palavras-chave: Ensino Médio; Percepção sobre Imunologia; Estudantes.

\begin{abstract}
This research analyzed the Immunology teaching-learning process at public and private schools at Itaperuna (RJ) municipality, looking for differences at this process and examines didactical materials and methodological procedures used by the teachers. The research involved students from the 3rd year of high school and their Biology teachers. It was applied a questionnaire about immunology for the students and was made an interview with the teachers to verify how this theme is approached at classroom and which didactical materials are used. The students hit less than $50 \%$ of the questions. We can conclude that students have a poor knowledge about Immunology, because of the low attention given by the teachers about it. This result shows the needing of discussion about the teaching process and about the alternative tools to stimulate the Immunology teaching-learning practices, as well to make the Immunology popular, once it is a daily common subject.
\end{abstract}

Keywords: Middle school; Immunology Perception; Students.

\section{Introdução}

A ciência e a biotecnologia são questões fundamentalmente presentes na vida cotidiana, apesar de muitas vezes não percebermos isto. Quando é noticiado, por exemplo, a produção de um novo medicamento no combate a alguma doença ou o desenvolvimento de uma nova vacina e sua a interação com os organismos, nota-se a presença crescente de produtos oriundos da ciência e tecnologia no meio social, o que torna o conhecimento sobre esta temática essencial para a interpretação do mundo ao nosso redor (ANDRADE et al., 2015). 
O estudo da Imunologia, assim como inúmeros outros temas em Biologia, tem avançado progressivamente, não apenas nas áreas básicas da Biologia, mas também em estudos complexos, como as respostas do hospedeiro a vários agentes infecciosos, a compreensão dos mecanismos que desencadeiam processos alérgicos, o rápido desenvolvimento de novas vacinas, dentre outros. Embora a relevância desta ciência no cotidiano seja reconhecida, poucos cidadãos são detentores do saber científico de forma organizada, compreendem os produtos oriundos das pesquisas científicas, e sabem avaliar as implicações da utilização dos mesmos (ARAÚJO-JORGE e BORGES, 2004). Infelizmente, a maioria da população brasileira encontra-se distante do conhecimento científico, sendo apenas consumidora destes produtos, o que os tornam incapazes de discutir amplamente a ciência. Consequentemente, esses cidadãos acabam sendo excluídos da possibilidade de tomar decisões críticas, pois sem dominar o conhecimento científico básico, deixam de atuar como agentes conscientes para decidir acerca dos fatos ao seu entorno e se tornam incapazes de exercer a cidadania (CHASSOT, 2006).

Roitman (2012) aponta que o Brasil vive uma profunda crise na educação científica, principalmente no ensino básico, fato impulsionado pela falta de subsídios para uma formação científica qualificada no ambiente escolar. Nessa conjuntura, é importante abordar sobre a Imunologia, uma vez que esta área apresenta extrema relevância para a vida humana e suas relações com o ambiente ao abordar diversos fenômenos que ocorrem em nosso organismo e a busca pela homeostase. Além disso, a Imunologia é um tema imprescindível na área da saúde pública, por tratar da dinâmica saúde-doença, o uso de vacinas, soros, medicamentos antialergênicos dentre outros. Infelizmente, podemos observar que tais processos não são amplamente compartilhados e compreendidos pelos estudantes e pela a população (CANTO e BARRETO, 2011; ANDRADE et al., 2015).

Como a ciência é um elemento que, conscientemente ou não, faz parte da vida de todo cidadão, necessita ser cada vez mais popularizada para permitir a oportunidade de acesso básico à mesma, principalmente no âmbito da divulgação fatores intrínsecos à saúde humana e sua relação com o meio ambiente (DEBARD et al., 2005; ANDRADE et al., 2015). No presente estudo, a Imunologia Básica será abordada como uma subárea que estuda os componentes biológicos atuantes nos processos imunológicos, sua dinâmica de funcionamento e inter-relações, em um processo que busca a homeostasia do organismo, ou seja, seu equilíbrio frente às mudanças externas ou internas (ABBAS et al., 2015; JANEWAY et al., 2006). Tal estado homeostático é caracterizado pelas relações indispensáveis para a manutenção do equilíbrio dinâmico do sistema vivo, ou seja, a estabilidade fisiológica (TORTORA e GRABOWSKI, 2006).

Um tema que têm sido alvo de debates e pesquisas mundiais é a concepção do mundo conceitual da criança e do adolescente, de que forma é realizada a percepção das modificações deste mundo durante o seu desenvolvimento e das experiências de aprendizagens, para que possam ser buscados métodos mais adequados para o ensino apropriado de diferentes áreas do conhecimento (SULEIMAN et al., 2015). Assim, para que o ensino-aprendizado da Imunologia se torne significativo, o professor precisa deixar de ser um mero informante dos conhecimentos científicos ou organizador das classificações biológicas e passe a investigar o que pensam os estudantes, a interpretar suas hipóteses, a considerar seus argumentos e a analisar suas experiências em relação aos contextos culturais (OLIVEIRA, 1999). Para aprender efetivamente, os discentes devem contar com a diversidade de tarefas, técnicas e recursos (SANMARTÍ, 2002).

Desta maneira, o professor deve somar os conhecimentos que os estudantes já possuem com novas informações sobre o tema para amplificar o conhecimento e para maximizar os horizontes da disciplina. Deve-se, portanto, utilizar de todos os recursos possíveis para reforçar a necessidade da interação, não arbitrária e não literal, entre materiais, mecanismo de aprendizagem, informações novas e os conhecimentos prévios dos discentes (AUSUBEL, 2003). É essencial conhecer as concepções prévias que os estudantes trazem nos níveis anteriores da educação formal, não formal e informal, estabelecer raciocínio lógico e abstrato para assim planejar estratégias 
didáticas adequadas ao aprendizado significativo, à construção e à mudança conceitual, com o qual é necessário trocar o foco da aprendizagem centrada exclusivamente no conteúdo para a aprendizagem centrada no aluno (DI CARLO, 2006). Segundo Vigostski (2008) "Um conceito se forma mediante uma operação intelectual em que todas as funções mentais elementares participam de uma combinação específica". Desta forma que, por exemplo, conceitos como "vontade celular" serão substituídos por "tropismo de um linfócito à um antígeno" pelos estudantes.

Aprender a questionar ensinamentos escolares nos leva a compreender as contradições da escola (LOPES, 1999), como as Ciências são tratadas na escola, como são formados seus currículos e como os discursos técnico-científicos são transformados em discurso escolar, às vezes, genéricos, esvaziados de seus conteúdos originais. Assim, Lopes (2000) releva que "a disciplina escolar não representa obrigatoriamente o mesmo sistema de pensamento, métodos de investigação, proposições e conceitos dos campos científicos". Um distanciamento que nos permite ver que, muitas vezes, as atividades de classificação e resolução de problemas são feitas segundo objetivos sociais estabelecidos para o contexto pedagógico aos estudantes, por isso, muitas vezes o docente ao tentar fugir do emprego técnico, deixa de observar muitos detalhes importantes para o aprendizado do estudante, como por exemplo, a investigação, a redescoberta e o raciocínio lógico e abstrato. Atividades laboratoriais e práticas podem ser grandes agentes precursores de uma melhoria no entendimento da disciplina, além ainda de promover interação social entre grupos, gerando um avanço significativo no aprendizado dos estudantes (TANNER e ALLEN, 2005).

Apesar de a ciência Imunologia ter pouco tempo de progressão e ao mesmo tempo ter rendido um arsenal surpreendente de conhecimento gerado nas últimas décadas do século XX, a base microbiológica da origem da Imunologia é o senso comum e predomina na concepção dos estudantes participantes do trabalho e dos autores dos livros analisados feito por Barreto e Teixeira (2013), em que a maioria dos livros didáticos e de alunos recém formados no Ensino Médio tem como papel central e primordial da resposta do Sistema Imunológico na defesa contra microorganismos, sem haver qualquer consideração por sua participação na homeostasia do indivíduo. Portanto, deve-se haver uma busca de alternativas, essas que fazem repensar na Imunologia em termos de novos modelos, em termos de homeostase e interdependência, talvez mais propícios à abordagem das questões que ora se impõem nos seus horizontes, com inquestionáveis efeitos na educação (SIQUEIRA-BATISTA, 2008).

Diante deste cenário propomo-nos a avaliar como é realizado o processo de ensinoaprendizagem do tema Imunologia no o Ensino Médio tanto por escolas públicas quanto privadas e avaliar se há divergências na abordagem do tema entre ambas as modalidades de ensino. Também foram analisados os procedimentos metodológicos do corpo docente com relação ao ensino de Imunologia bem como os materiais didáticos e os recursos oferecidos pelas instituições de ensino.

\section{Material e Métodos}

O público alvo desta pesquisa foram três turmas do $3^{\circ}$ ano do Ensino Médio de escolas públicas e em três turmas do $3^{\circ}$ ano do Ensino Médio de escolas privadas do município de Itaperuna (RJ). Foram analisados 61 alunos de instituições particulares e 64 alunos de instituições públicas, gerando um total de 125 alunos analisados através da aplicação de um questionário contendo 10 questões fechadas e básicas sobre Imunologia (apêndice 1). O questionário foi aplicado no $3^{\circ}$ ano do Ensino Médio no ano de 2015. A análise realizada para este estudo foi do tipo descritiva com enfoque tanto qualitativo como e quantitativo. Foi escolhida a modalidade de pesquisa com questões fechadas, pois, apesar de não estimular a originalidade, a variabilidade e concentração, elas têm as vantagens de serem aplicadas rapidamente, com facilidade, uniformidade e auxilia na categorização das respostas, contextualizando melhor a pesquisa. 
O trabalho também contou uma entrevista contendo com cinco perguntas abertas aos professores de Biologia das turmas de cada instituição (apêndice 2), com o intuito analisar as aplicações metodológicas da disciplina em cada escola (como é realizado, se é realizado e qual a frequência de estudos da disciplina de Imunologia etc.), bem como avaliar o destaque dado a esta disciplina ao longo da jornada de aprendizagem dos estudantes. Toda a pesquisa foi realizada com prévia anuência da direção de cada escola e os estudantes foram esclarecidos quanto à sua liberdade de participação ou não no projeto (termo de consentimento livre e esclarecido).

\section{Resultados e Discussão}

\subsection{Análise do conhecimento sobre Imunologia por estudantes do Ensino Médio}

As respostas obtidas da aplicação do questionário foram quantificadas e tabuladas para melhor análise dos dados. Quando questionados sobre "O que seria imunidade" (questão 1) cerca de $45 \%$ e $35 \%$ dos estudantes das escolas privadas e públicas, respectivamente, responderam corretamente a alternativa: "Estado de resistência às doenças, geralmente infecciosas" (figura 1). Foi possível observar que a maioria dos estudantes respondeu incorretamente à questão em ambas as modalidades de ensino (figura 1), marcando as alternativas incorretas: "Capacidade de criar muitas células"; "Estado de proteção total do corpo humano"; "Estar protegido contra um agente infeccioso específico". Muitos alunos possuem incerteza à definição de imunidade, geralmente confundindo-a com o termo estar imune, ou seja, estar protegido contra um patógeno específico. Tal questão básica não deveria ser confundida pelos estudantes, o que demonstra uma clara deficiência quanto ao conceito básico de imunidade.

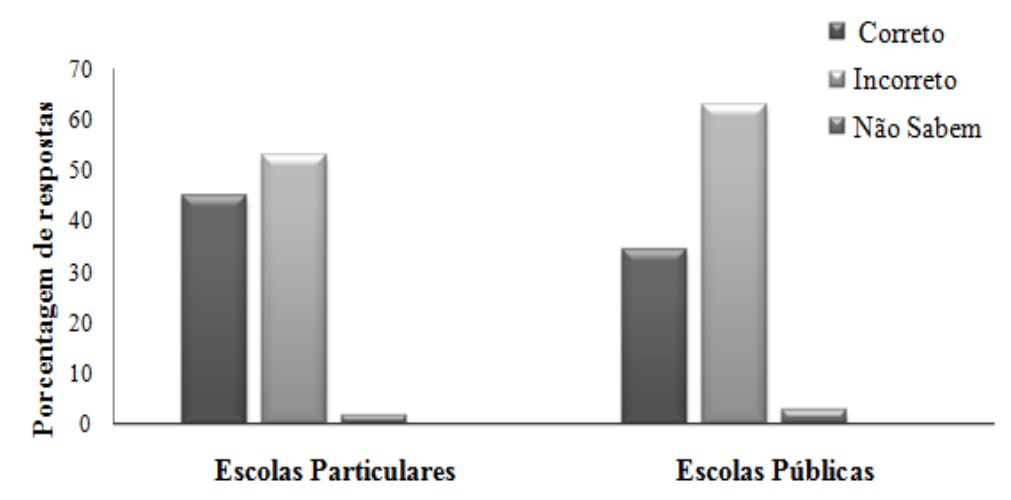

Figura 1: Respostas dos estudantes para a questão: "Para você, o que é imunidade?"

$\mathrm{Na}$ segunda questão, que basicamente pergunta o porquê das células do Sistema Imunológico não atacarem as células/moléculas do próprio corpo, a maioria dos estudantes de escolas privadas (75\%) e cerca de metade dos estudantes de escolas públicas (55\%) marcaram a opção correta (figura 2): "Porque elas têm a capacidade de reconhecer as moléculas que são do próprio corpo e as que não são". Nesta questão houve pequenas variações nas respostas incorretas dadas pelos estudantes, em que muitos optaram pela assertiva: "Porque o corpo humano é mais forte e maior". O conhecimento biológico tem como fonte primordial os alicerces do ensino de ciências e seus princípios fundamentais, como por exemplo, o das funções biológicas não apresentarem um controle consciente, dessa forma, esta questão indica que o aluno ainda não identifica que as unidades microscópicas do nosso sistema (moléculas, organelas, dentre outros) não atuam com sua própria vontade, mas sim com a taxia físico-química que a natureza exerce em convergência com a termodinâmica (JANEWAY et al., 2006, 2015). 


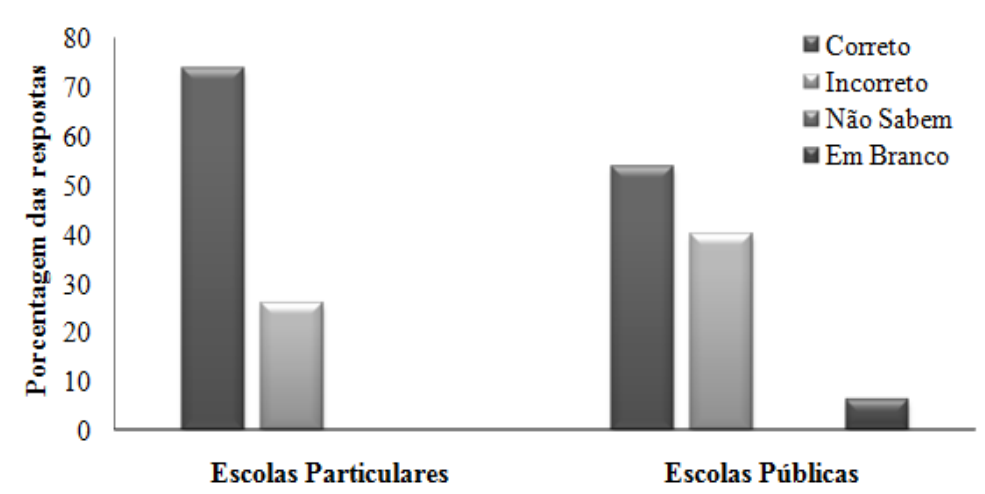

Figura 2: Respostas dos estudantes para a questão 2: "Você sabe por que as células do Sistema Imunológico não atacam as células/moléculas do próprio corpo?"

Quando indagados sobre os transplantes de órgão e a imunidade ("O que propiciaria o transplante de órgãos entre indivíduos diferentes? "), menos da metade dos estudantes (40\% dos estudantes das escolas particulares e 30\% dos estudantes das escolas públicas) marcaram a alternativa correta ("A existência de compatibilidade tecidual"), como observado na figura 3. A maioria de ambas as categorias de ensino assinalaram incorretamente que o transplante de órgãos entre indivíduos diferentes é possível devido a "compatibilidade imune”, enquanto muitos outros optaram por "compatibilidade genética”. É óbvio que estudantes do Ensino Médio não saberão conceitos técnicos do MHC (Major Histocompatibility Complex) com os TCR's (Receptores de Células T) ou de rejeições entre órgãos, mas deveriam saber conceitos biológicos de como basicamente acontece a aceitação entre células de outros indivíduos, ou o estudo pelo menos superficialmente da abordagem de reconhecimento do não-próprio pelas células do sistema imunológico (ABBAS et al., 2015).

$\mathrm{Na}$ questão 4 os alunos deveriam marcar a alternativa em que eles acreditavam ser células do Sistema Imunológico. Dentre as opções havia "Leucócito, hemoglobina e neurônio"; "Proteína, hemácia e aminoácido"; "Vacúolo, hepatócitos e insulina"; "Macrófago, linfócito e neutrófilo"e a opção "Não sei". Foi observado que 53\% dos alunos das escolas particulares e $50 \%$ das públicas marcaram a alternativa correta nesta questão (Macrófago, linfócito e neutrófilo). Muitos ainda acreditam que "hemoglobina e neurônio", "proteína e aminoácido" ou "vacúolo e insulina" fazem parte do sistema imunológico, compondo $44 \%$ das repostas da rede privada e $48 \%$ da rede pública.

Esta pergunta analisa o conhecimento dos alunos sobre diferenciar organelas, macromoléculas, células do sistema imunológico e demais células do corpo humano e, mesmo sendo uma questão óbvia para professores, ainda mostra que muitos formandos do Ensino Médio não o sabem; como Patrícia e Lourenço (2012) releva, a pobre carga de informação científica de recém aprovados em cursos de ciências da vida, provém de aulas ou conteúdos insuficientes nos materiais didáticos durante o Ensino Médio. 


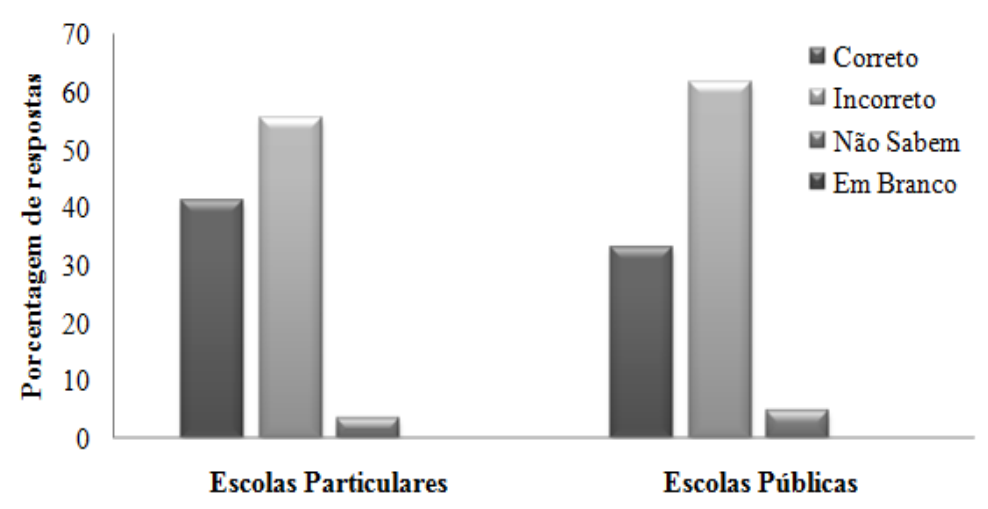

Figura 3: Porcentagem de respostas dos estudantes para a questão 3: “O que propicia o transplante de órgãos entre indivíduos diferentes?” entre escolas particulares e públicas.

Quando perguntados sobre “O que seria um patógeno?”(questão 5), em ambas as instituições, houveram escolhas variadas de respostas como "Agente do próprio corpo", "Célula hospedeira"e "célula cancerígena", totalizando aproximadamente $45 \%$ das respostas incorretas dos estudantes da rede privada e 55\% dos estudantes da rede pública. O termo patógeno, apesar de ser técnico, deveria ser conhecido pelos estudantes, uma vez que os mecanismos de diversas doenças causadas por patógenos são abordadas no Ensino Médio, como no Livro Biologia Série Brasil de Linhares e Gewandsznajder (2005) com uma infinidade de nomenclatura e reações. Assim, diferenciar um patógeno de agente próprio (self), ou de uma célula hospedeira não deveria ser um problema a ser respondido.

Na questão 6, que perguntava "Você sabe como podem ser feitas as vacinas contra um tipo de bactéria?", houve um surpreendente baixo número de acertos, em que a resposta correta seria: "Bactérias inativas"(50\% pelos estudantes das escolas particulares e 56\% de acerto dos estudantes das escolas públicas). Poucos alunos optaram pela opção "Drogas específicas", porém a opção com maior quantidade de erros foi "Antibióticos". Oito estudantes marcaram a opção "Nutriente", o que revela a completa desinformação sobre o conteúdo em plena finalização do Ensino Médio.

Um dos assuntos mais abordados nos livros didáticos do Ensino Médio são vacinas (BARRETO e TEIXEIRA, 2013). Praticamente todos já tiveram contato, já leram ou ouviram falar, mas ainda não sabem definir como são feitas. Uma aula pode ser facilmente preparada se pensarmos rapidamente o funcionamento das vacinas e como ela foi descoberta, sem muitas delongas, e com informações/conhecimentos fornecidos pelos próprios estudantes. Estes resultados demonstram o qual superficial este assunto é tratado em sala de aula, em reflexo do grande número de respostas incorretas $(50 \%$ e $42 \%$ dos estudantes da rede particular e pública, respectivamente).

Quando questionados sobre as diferenças entre vacina e soro terapêutico (figura 4), cerca de $50 \%$ dos alunos das escolas privadas marcaram a resposta correta, enquanto que, de forma assustadora, apenas $35 \%$ dos alunos das escolas públicas a acertaram. A opção errada que foi mais marcada foi: "Vacina é para prevenir doença e soro é para tratar doenças". Muitos alunos ainda marcaram: "Soro serve para hidratar o paciente"; ou então "Vacina e soro são a mesma coisa". Complementando a pergunta anterior, esta questão ressalta o debilitado conhecimento dos estudantes de Ensino Médio sobre as vacinas e soros, em que as vacinas seriam responsáveis pela produção de anticorpos no organismo, enquanto o soro terapêutico contém anticorpos específicos para combater a doença ou a intoxicação, como por exemplo, por picadas de cobras (MESQUITA, 2006). 


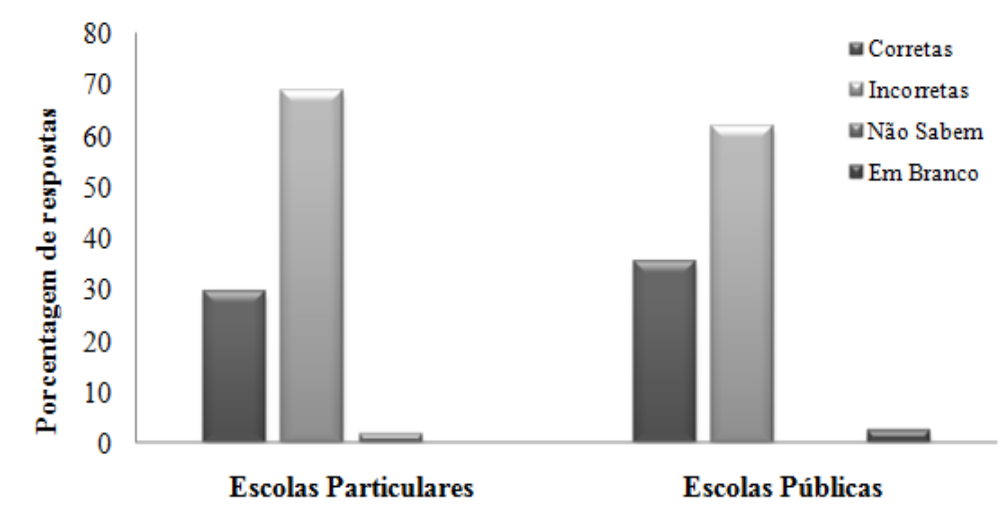

Figura 4: Respostas dos estudantes para questão 7 (“A diferença entre vacina e soro terapêutico é”) entre as escolas particulares e públicas.

A questão 8 (“'O que é um anticorpo?") foi que estudantes obtiveram menos acertos tanto nas escolas particulares (30\%) quanto nas públicas (25\%). Muitos estudantes ainda não entendem o verdadeiro funcionamento das imunoglobulinas, confundindo-as com: "Fagócitos", ou "Antígenos" ou mesmo "Moléculas com auto-capacidade de detectar agentes infecciosos no organismo". Mesmo sendo um assunto comum nos livros didáticos (até mesmo em livros com escassez de informações), um número grande de discentes (67\% e $72 \%$ de estudantes de escolas privadas e públicas, respectivamente) não souberam identificar o conceito correto de anticorpo.

Anticorpos primeiramente não são células. São grandes moléculas protéicas com capacidade de reconhecer o non-self, ou seja, o que não pertence ao próprio sistema (OLIVEIRA e KANASHIRO, 2010). Dessa forma, como abordado em outra pergunta, os anticorpos não detectam o corpo estranho, mas por ser produzido em demasia numa infecção, irá se ligar ao agente infeccioso quando se aproximarem, desencadeando uma reação para neutralizar e eliminar o mesmo. As ligações e transformações de energia no meio químico não acontecem por mera vontade das moléculas, mas sim pelo acaso e por quimiotaxia (JANEWAY et al., 2006, 2015). Desta forma, observa-se um baixo resultado no conhecimento dos estudantes quanto à natureza dos anticorpos.

A pergunta 9, questionava sobre um evento corriqueiro no dia a dia dos estudantes ("Um forte arranhão, com sintomas de vermelhidão, dor, inchaço e calor, é:”). Os alunos das instituições particulares obtiveram muito mais acertos que os alunos das instituições públicas, porém, em ambas, mesmo sendo um questionário sobre imunologia, alguns não souberam identificar a resposta correta, ou seja, "Inflamação". Muitos ainda marcaram: "Úlcera", "Envenenamento" e "Queimadura" (figura 5).

Sintomas de inflamação é outro tema de suma importância a ser abordado em aulas, pelo menos, do Ensino Médio, pois explica que moléculas ou células nos lugares errados (quando acontece, por exemplo, um arranhão forte), podem influenciar numa reação imunológica, pois fatores lipídicos e citoplasmáticos causaram tais reações (OLIVEIRA E KANASHIRO, 2010; ABBAS et al., 2015). Desta forma, observamos que uma inflamação não é apenas causada por doenças ou viroses, o que tem evidenciado conflito nas respostas dos estudantes. 


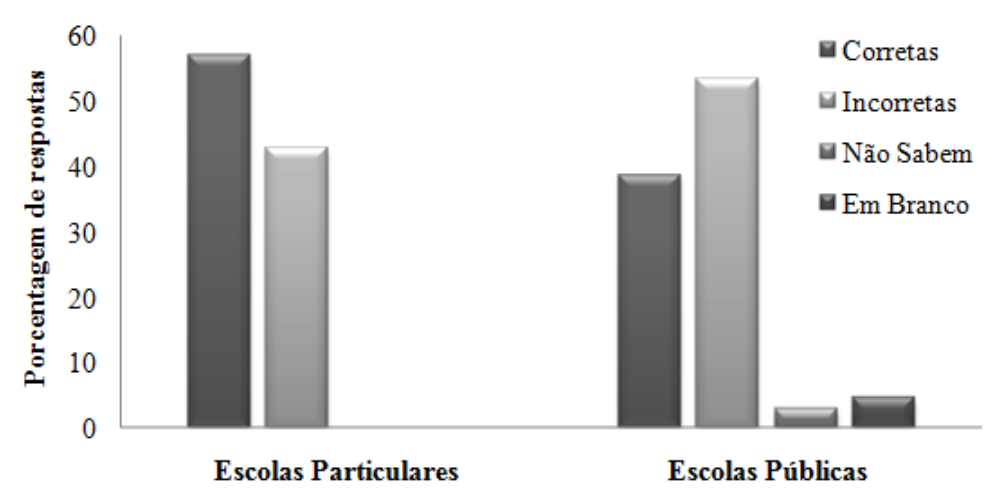

Figura 5: Porcentagem de respostas dadas para a questão 9 ("Um forte arranhão, com sintomas de vermelhidão, dor, inchaço e calor, é”).

Na questão 10 (“Qual a importância do Sistema Imunológico?”) em ambas as categorias de ensino, poucos alunos marcaram a opção correta: "Manter o equilíbrio e proteger o organismo" (figura 6). O número maior de erros desta questão foi a daqueles estudantes que consideraram o Sistema Imunológico apenas como "Protetor do organismo", descartando a importância na homeostase do mesmo. O sistema imunológico, além de contribuir a manter a homeostase química no sistema, o protege contra produtos não próprios (non-self), sendo ele orgânico ou inorgânico, tóxico ou atóxico, unicelular ou pluricelular, Fungi, Plantae, dentre outros. Como exemplo, o repertório estimado de anticorpos é de 8,4 x $10^{10}$ a 7,6 x 10 11 (OLIVEIRA E KANASHIRO, 2010). A beleza como a Biologia descreve, em especial a área da Imunologia, ou seja, com ações caóticas e ao mesmo tempo perfeitas, devem ser analisadas com certo carinho e transmitidas, se possível através de estimulação de redescoberta ou raciocínio crítico e abstrato, pois a informação só vira conhecimento quando é interpretada e usada.

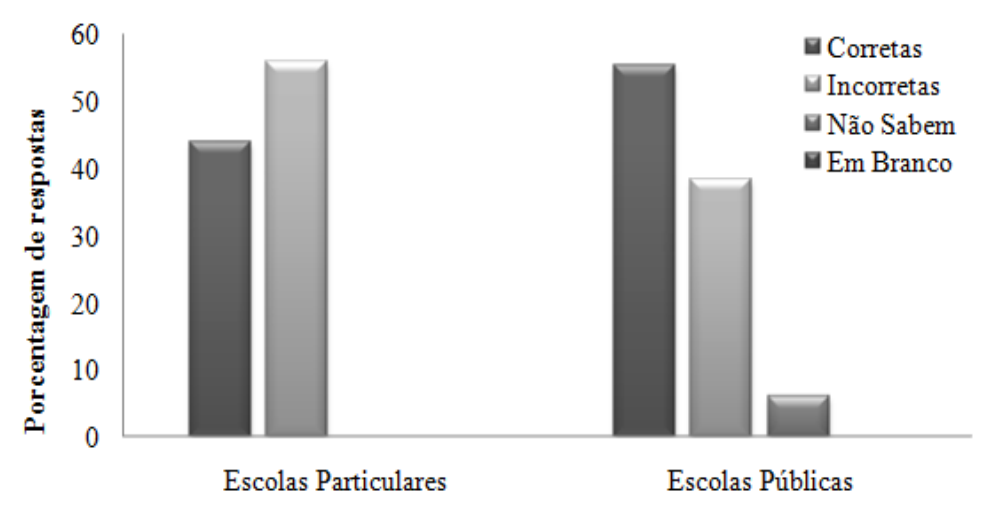

Figura 6: Porcentagem de respostas da questão 10 ("Qual a importância do Sistema Imunológico?”) nas escolas particulares e públicas.

\subsection{Análise da abordagem do tema Imunologia em sala de aula}

A entrevista com os professores de cada instituição foi realizada conforme o apêndice 2. Na primeira pergunta da entrevista, os professores foram indagados se são ministradas aulas de Imunologia durante o Ensino Médio naquela escola em questão. Esta pergunta serviria de apoio à avaliação das respostas dos estudantes conforme a realização ou não de aulas de Imunologia no Ensino Médio. A Imunologia é uma ciência interdisciplinar dentro da área da saúde e, devido a sua importância para a sociedade, é que se encontra inserida como conteúdo dos programas curriculares, daí a necessidade de saber do próprio professor se são aplicadas aulas da referida disciplina no Ensino Médio. 
Todos os docentes de instituições particulares confirmaram que aplicam aulas de Imunologia no Ensino Médio, porém em uma delas, o docente especificou que este tema é abordado com "conceitos superficiais, de forma bastante básica". Duas das instituições públicas responderam que ministram aulas do referido tema no Ensino Médio e, de forma surpreendente, uma escola respondeu que não. Ao se aplicar os conceitos de forma superficial e ao não de ministrar aulas de imunologia pode ser preocupante, pois duas das seis instituições estudadas negligenciam conhecimentos imprescindíveis deste tema, o que têm reflexo direto com os resultados obtidos no questionário dos estudantes.

Posteriormente foram questionados aos docentes quais os principais temas em Imunologia são ministrados no Ensino Médio. Uma parte dos professores respondeu que dão aulas básicas sobre doenças sexualmente transmissíveis, vacinas e células que compõem o Sistema Imunológico. Outra parte afirmou que ministravam aulas sobre a origem e funcionamento de vacinas, os tipos de células de defesa do organismo e sua atuação no corpo humano, o desenvolvimento de alergias ou hipersensibilidade, como é organizado o sistema imune, propriedades gerais do sistema de defesa do corpo humano, como ocorrem infecções e a causa de rejeições em transplantes de órgãos.

É impressionante que, com uma diversidade ímpar de temas a serem ministrados em Imunologia, ainda assim as aulas são pouco exploradas juntamente com os estudantes, o que os limita em obter acesso ao conhecimento sobre o mecanismo de defesa do corpo humano e as tecnologias desenvolvidas pela ciência dentro da referida área, contribuindo de maneira direta na formação de cidadãos com baixo domínio sobre o conhecimento biotecnológico e suas implicações no cotidiano, impedindo-os de buscar uma reflexão sobre as relações entre a ciência, a tecnologia e a sociedade (BRASIL, 2000).

Nesta pesquisa também pudemos observar que cinco das seis escolas responderam que aplicam aulas sobre anticorpos no Ensino Médio, ou seja, mesmo que somente cerca de $30 \%$ dos alunos marcaram a resposta correta na questão 8 ("O que é um anticorpo?"), 83\% das escolas analisadas responderam que aplicam o referido tema como principal. A pouca importância dada aos temas no ensino de Imunologia durante o Ensino Médio resulta na escassez de conhecimentos específicos pelos alunos formandos, o que leva a resultados tão baixos como no questionário, o que demonstra a dificuldade na associação entre ciência e tecnologia, áreas que estão se tornando cada vez mais presentes no cotidiano e modificando cada vez mais o mundo e o próprio ser humano.

Quando os professores foram perguntados como são os materiais didáticos para o ensino de Biologia, esperávamos duas respostas: a primeira seria de apenas materiais fornecidos pela instituição de ensino, seguindo o mesmo problema descrito por Barreto e Teixeira (2013), ou seja, com pouca informação sobre o tema e limitando o ensino com as informações contidas no material; e a segunda seria através de materiais fornecidos pela instituição e, além disto, de materiais próprios, como apostilas, pesquisas de diversas fontes telecomunicativas e outras. Através destas respostas, podemos propor melhorias ou auxiliar na busca por fontes de informações para essas aulas no Ensino Médio, visto que esta pergunta também surte efeito nas respostas dos estudantes sobre o ensino de Imunologia.

As instituições públicas responderam que utilizam exclusivamente materiais didáticos para o ensino de Biologia fornecido pelas escolas. As instituições particulares responderam que além dos materiais disponibilizados pelas escolas, utilizam de recursos próprios, como apostilas, slides dentre alguns outros. Além de materiais fornecidos pelas instituições, o professor, ao utilizar recursos extras teria uma carga maior de conhecimento para ser compartilhado com os estudantes, e muitas vezes informações de maior facilidade de assimilação com o dia a dia do estudante, fazendo com que ele se transporte de um cenário meramente científico para um contexto em que estão envolvidos vários aspectos da vida humana (BRASIL, 2000). Segundo Tanner e Allen (2005), evitando padrões didáticos como ter de seguir sempre a um currículo pré-determinado, 
auxilia no entendimento e possibilita ao aluno abranger a informação no ambiente em que vive. Porém, pode-se observar que, apesar do professor utilizar-se de recursos extras, o nível de respostas dos estudantes do ensino privado em pouco diferiu do público, demonstrando uma possível necessidade de capacitação dos docentes para a melhoria das suas aulas utilizando-se outros recursos para o aprendizado.

Assim como a pergunta anterior, a pergunta "Há aplicações de outras metodologias no ensino de Biologia? Se sim, quais?" Define a riqueza de como o ensino de Biologia é abordado no Ensino Médio. É possível que instituições tenham material/laboratórios para metodologias diversas de ensino, contudo, pode ser que o professor de biologia não os use efetivamente. Todas as instituições responderam que aplicam diversas outras metodologias para o ensino de Biologia no Ensino Médio. Todas especificaram aulas laboratoriais, exposição de vídeo e uso da internet. Algumas instituições particulares ainda incrementaram uso de lousa eletrônica, data show, aulas práticas, visitas técnicas, pesquisas e exposição.

$\mathrm{Na}$ última pergunta os professores foram questionados se "Os alunos desta instituição, ao formarem-se, terão uma concepção refinada da Imunologia? Porquê? ". Esta questão exige sinceridade do professor, pois o mesmo fechará a pesquisa dizendo se o ensino de Imunologia está sendo eficiente ou não no Ensino Médio, portanto, sendo demonstrado pelas respostas dos estudantes no questionário. Isso também faz o professor refletir como está sendo a metodologia de ensino, não apenas na área de Imunologia, mas de todo ramo em Ciências Biológicas no Ensino Médio da referida instituição.

Um dos professores de uma escola particular respondeu que os alunos terão uma "concepção básica" de imunologia ao formarem-se; outra instituição particular respondeu que terão "ótima concepção, pois o material é completo e a carga horária satisfaz o professor"; a última escola particular respondeu que terão uma "boa concepção, pois o recurso didático da escola é ótimo". Os três docentes das escolas públicas responderam que os alunos terão uma "concepção básica", uma "baixa concepção" ou uma "boa concepção". Todos os resultados demonstrados neste trabalho demonstram a necessidade de uma reflexão por parte dos docentes sobre como este tema é ministrado em suas aulas, uma vez que podemos observar pelas respostas dos estudantes que o aprendizado não é efetivo, mesmo nas escolas onde os professores afirmam utilizar os recursos didáticos mais variados e que apresentam um material didático excelente. Foi claramente visível que os estudantes não possuem domínio sobre conhecimentos básicos em Imunologia, o que nos leva a notar a necessidade urgente de mudanças no ensino desta temática no Ensino Médio.

\subsection{Análise dos resultados gerais das respostas dos estudantes}

As respostas dadas pelos estudantes das escolas particulares e públicas ao questionário demonstraram um resultado insatisfatório, onde apesar de as escolas particulares tiveram um pouco mais de acertos que as escolas públicas, ambas ficaram muito abaixo da média esperada, totalizando cerca de $50 \%$ dos acertos em instituições privadas e por volta de $45 \%$ em instituições públicas. A entrevista com os professores de Biologia das instituições revela que o tema Imunologia é sim aplicado no Ensino Médio (com exceção de uma escola), mas com conteúdo empobrecido da matéria, pois todas as escolas possuem recursos metodológicos suficientes para a elaboração de aulas dinâmicas e materiais diversos fornecidos ou não pelas mesmas.

\section{Conclusão}

Os resultados sugerem que há poucas diferenças no ensino de Imunologia entre as escolas particulares e públicas no Ensino Médio no município de Itaperuna (RJ), e, ainda que as instituições analisadas possuam recursos didáticos e paradidáticos necessários para executarem 
aulas enriquecidas e dinâmicas, as aulas ainda são pobres e bastante conceituais. Respostas a um questionário não podem calcular com exatidão o nível intelectual ou o conhecimento adquirido dos estudantes analisados, mas serve como uma ferramenta para meditação sobre a boa aplicação do ensino de Imunologia e se este está sendo potencialmente trabalhado no Ensino Médio no município.

Os níveis de acertos abaixo de $50 \%$ somados ao baixo grau de dificuldade de responder às questões nos revelam que o processo de ensino-aprendizagem ainda está aquém do que pode ser considerado um bom ensino de Imunologia, pois cada questão foi minuciosamente elaborada a fim de testar os conhecimentos não técnicos adquiridos com informações consideradas básicas no tema analisado ao final do Ensino Médio.

Todas as instituições informaram que ministram aulas de Imunologia no ensino de Biologia no Ensino Médio, com exceção de uma, e todas informaram que há recursos de materiais distintos, laboratórios científicos, laboratórios de informática, salas de vídeo e recursos para a realização de exposições. Logo estas possuem capacidade para a criação de projetos, feiras científicas, pesquisas acadêmicas, palestras, dentre muitos outros, e, mesmo assim não exploram estes recursos. $\mathrm{O}$ professor deve sempre ser o mediador de conhecimento, explorando o que os alunos já sabem e fundindo estes conhecimentos, de forma a fazer os estudantes compreenderem a beleza da ciência e suas aplicações no dia a dia.

\section{Referências}

ABBAS, A. K.; LICHTMAN, A. H.; PILLAI, S. H. I. V. Imunologia celular e molecular. 8.ed. Rio de Janeiro: Elsevier, 2015.

ANDRADE, V. A.; PAULA, L. M. NICOLINI, L. B.; ARAÚJO-JORGE, T. C.; COUTINHOSILVA, R. A Imunologia no segundo segmento do Ensino Fundamental Brasileiro. Ciências \& Cognição, v. 20, n. 1, p. 142-154, 2015.

ARAÚJO-JORGE, T. C.; BORGES, E. L. A expansão da pós-graduação na Fundação Oswaldo Cruz: contribuição para a melhoria da educação científica no Brasil. Revista Brasileira de Pós-Graduação, v. 1, n. 2, p. 97-115, 2004.

AUSUBEL, D. P. Aquisição e Retenção de Conhecimentos: Uma Perspectiva Cognitiva. Lisboa: Plátano Edições Técnicas, 2003.

BARRETO, C. M. B. \& TEIXEIRA, G. A. P. B. Concepções prévias de universitários sobre o sistema imunológico. Revista Brasileira de Ensino de Ciência e Tecnologia, v. 6, n. 1, p. 1-18, 2013.

BRASIL. Ministério da Educação. Secretaria de Educação Média e Tecnológica. Parâmetros Curriculares Nacionais (Ensino Médio). Brasília: MEC, 2000.

CANTO, F. B.; BARRETO, C. M. B. O vídeo como ferramenta didático-pedagógica sensibilizadora para o aprendizado de Imunologia. Revista Aleph, v. 5, n. 15, p.1-26, 2011. CHASSOT, A. Alfabetização científica: questões e desafios para a educação. Ijuí: Editora UNIJUÍ, $1^{\text {a }}$ ed., 2000.

DEBARD, N.; PY, P.; KRAEHENBUHL, J. P.; FUCHS, J. The influence of the Internet on immunology education. AOP Nature Reviews Immunology, v. 5, n. 9, p.1-5, set. 2005. 
DICARLO, S. E. Cell biology should be taught as science is practised. Nature Reviews Molecular Cell Biology, v. 7, p. 290-296, 2006.

JANEWAY, C. A.; SHLOMCHIK, M. J.; TRAVERS, P. WALPORT, M. Imunobiologia: o

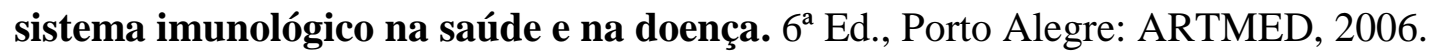

LINHARES, S.; GEWANDSNAJDER, F. Biologia, $3^{\text {a }}$ ed. Editora Ática, 2005.

LOPES, A. R. C. Conhecimento escolar: Ciência e cotidiano. Rio de Janeiro: Eduerj, 1999.

LOPES, A. R. C. Organização do conhecimento escolar: analisando a disciplinaridade e a integração. In: CANDAU, V. M. Linguagens, espaços e tempos no ensinar e aprender. Rio de Janeiro: DP\&A, 2000.

MESQUITA, M. Soro x Vacina. Disponível em http://www.unimed.coop.br/pct/index.jsp?cd_ canal $=46078 \&$ cd_secao=34474\&cd_materia=37321, Acessado em 28/04/2017.

OLIVEIRA, D. L. Ciências nas salas de aula. Porto Alegre: Mediação, 1999.

OLIVEIRA, L. B.; KANASHIRO, M. M. Imunologia. Vol.1/módulo 1. Rio de Janeiro: Fundação CECIERJ, 232 p., 2010.

PATRÍCIA, F., LOURENÇO, F. O Ensino de Imunologia dos Principais Métodos e Recursos Didáticos Utilizados em Universidades Brasileiras. $2^{\circ}$ Fórum Internacional Sobre Prática Docente Universitária, UFU, p. 483-490, 2012.

ROITMAN, I. Educação científica - quanto mais cedo melhor. Ed. RITLA, 2012. Disponível em: http://academiadeciencia.org.br/site/wp-content/uploads/2012/04/educacaocientifica-quantomais-cedo-melhor.pdf, acessado em 22/03/2017.

SANMARTÍ, N. Didáctica en las ciências y en la educación primaria. Madrid: Síntesis, 2002. SIQUEIRA-BATISTA, R.; GOMES, A. P.; ALBUQUERQUE, V. S.; MADALON-FRAGA, R.; ALEKSANDROWICZ, A. M. C.; GELLER, M. Ensino de Imunologia na Educação Médica, Lições de Akira Kurosawa. Revista Brasileira de Educação Médica. v. 33, n. 3, p. 186-190, 2008.

SULEIMAN, A. R. As concepções de alunos da $2^{\text {a }}$ série do ensino médio sobre as dificuldades em matemática. Educação em Revista, v. 16, n. 2, p. 97-116, Jul.-Dez., 2015.

TANNER, R. K.; ALLEN, D. Approaches to Biology Teaching and Learning: Understanding the Wrong Answers - Teaching Toward Conceptual Change. Cell Biology Education, v. 4, p.112-117, 2005.

TORTORA, G. J.; GRABOWSKI, S. R. Corpo humano - fundamentos de anatomia e fisiologia. Porto Alegre: Artmed, 2006.

VIGOTSKI, L. S. Pensamento e Linguagem. São Paulo: Martins Fontes, 2008. 


\section{APÊNDICE 1: Questionário Aplicado aos Estudantes}

1) Para você, o que é imunidade?

( ) Capacidade de criar muitas células.

( ) Estado de proteção total do corpo humano.

( ) Estar protegido contra um agente infeccioso específico.

( ) Estado de resistência à doenças, geralmente infecciosas.

( ) Não sei.

2) O Sistema Imunológico humano consiste numa rede de células, tecidos e órgãos que atuam na defesa do organismo contra o ataque de invasores externos, como microorganismos ou agentes nocivos, como substâncias tóxicas (ex. veneno de animais peçonhentos). Você sabe por que as células do Sistema Imunológico não atacam as células/moléculas do próprio corpo?

( ) Porque elas sabem o que é para atacar, vão ao alvo certo.

( ) Porque o corpo humano é mais forte e maior, não tendo chance nenhuma de ataque.

( ) Porque elas têm a capacidade de reconhecer as moléculas que são do próprio corpo e as que não são.

( ) Porque os invasores vão aos lugares onde as células do Sistema Imune estão.

( ) Não sei.

3) O que propicia o transplante de órgãos entre indivíduos diferentes?

( ) A existência da compatibilidade celular, ou seja, mesmas proteínas expressas nas superfícies celulares.

( ) A existência da compatibilidade imune, ou seja, mesmos tipos de células e moléculas do sistema imunológico.

( ) A existência da compatibilidade tecidual, ou seja, mesmo com mesmo tipo de tecido propicia o transplante.

( ) Compatibilidade genética. Mesmo material genético.

( ) Não sei.

4) Você acredita que são células do Sistema Imunológico:

( ) Leucócito, hemoglobina, neurônio.

( ) Proteína, hemácia, aminoácido.

( ) Vacúolo, hepatócitos, insulina.

( ) Macrófago, linfócito, neutrófilo.

( ) Não sei.

5) O que é um patógeno?

( ) Agente do próprio organismo.

( ) Célula hospedeira.

( ) Célula cancerígena.

( ) Agente causador de doenças.

( ) Não sei.

6) Você sabe como podem ser feitas as vacinas contra um tipo de bactéria?

( ) De drogas específicas.

( ) Da bactérias inativas.

( ) De antibióticos.

( ) De nutrientes.

( ) Não sei. 
7) A diferença entre vacina e soro terapêutico é:

( ) Vacina é para prevenir doença e soro é pra hidratar.

( ) Vacina vai produzir anticorpos e soro já possui anticorpos.

( ) Vacina é para prevenir doença e soro é para tratar doença.

( ) Vacina e soro é a mesma coisa.

( ) Não sei.

\section{8) O que é um anticorpo?}

( ) São células com capacidade de se ligar, fagocitar e destruir um agente infeccioso.

( ) São proteínas capazes de reconhecer moléculas que não pertencem ao nosso organismo.

( ) São proteínas que detectam apenas moléculas infecciosas.

( ) São corpos estranhos no organismo capaz de causar infecção.

( ) Não sei.

9) Um forte arranhão, com sintomas de vermelhidão, dor, inchaço e calor, é:

( ) Sintomas de úlcera.

( ) Sintomas de inflamação.

( ) Sintomas de envenenamento.

( ) Sintomas de queimadura.

( ) Não sei.

\section{0) Qual a importância do Sistema Imunológico?}

( ) Garantir a integridade do sistema sanguíneo.

( ) Proteger o organismo.

( ) Manter o equilíbrio e proteger o organismo.

( ) Destruir vírus, bactérias e protozoários.

( ) Não sei.

\section{APÊNDICE 2: Perguntas Realizadas aos Professores}

Instituição de Ensino:

1) São aplicadas aulas de Imunologia no Ensino Médio?

2) Quais os principais temas em Imunologia são aplicados no Ensino Médio?

3) Como são os materiais didáticos para o ensino de Biologia?

4) Há aplicações de outras metodologias no ensino de Biologia? Se sim, quais?

5) Você acha que os alunos desta instituição, ao formarem-se, terão uma concepção refinada da Imunologia? Por quê? 